Article

\title{
A Review of Behavioral Energy Reduction Programs and Implementation of a Pilot Peer-to-Peer Led Behavioral Energy Reduction Program for a Low-Income Neighborhood
}

\author{
Jennifer Hoody ${ }^{1, *}$, Anya Galli Robertson ${ }^{2} \mathbb{D}$, Sarah Richard ${ }^{3}$, Claire Frankowski ${ }^{1,3}$, Kevin Hallinan ${ }^{1,3, *}$ (D), \\ Ciara Owens ${ }^{3}$ and Bob Pohl ${ }^{3}$ \\ 1 Department of Mechanical and Aerospace Engineering, University of Dayton, Dayton, OH 45469, USA; \\ cfrankowski3@gmail.com \\ 2 Department of Sociology, Anthropology, and Social Work, University of Dayton, Dayton, OH 45469, USA; \\ agallirobertson1@udayton.edu \\ 3 Clean Energy 4 All, Dayton, OH 45410, USA; Sarah.n.richard19@gmail.com (S.R.); \\ ciara.joyvin@gmail.com (C.O.); pohlbob@gmail.com (B.P.) \\ * Correspondence: jenn.hoody@gmail.com (J.H.); kevin.hallinan@udayton.edu (K.H.)
}

Citation: Hoody, J.; Galli Robertson,

A.; Richard, S.; Frankowski, C.;

Hallinan, K.; Owens, C.; Pohl, B. A

Review of Behavioral Energy

Reduction Programs and

Implementation of a Pilot

Peer-to-Peer Led Behavioral Energy

Reduction Program for a Low-Income

Neighborhood. Energies 2021, 14,

4635. https://doi.org/10.3390/

en14154635

Academic Editors:

Barbara Pawlowska and

Giuseppe T. Cirella

Received: 30 May 2021

Accepted: 26 July 2021

Published: 30 July 2021

Publisher's Note: MDPI stays neutra with regard to jurisdictional claims in published maps and institutional affiliations.

Copyright: (c) 2021 by the authors. Licensee MDPI, Basel, Switzerland. This article is an open access article distributed under the terms and conditions of the Creative Commons Attribution (CC BY) license (https:// creativecommons.org/licenses/by/ $4.0 /)$

\begin{abstract}
Utility-sponsored residential energy reduction programs have seen rapid advancement in the Unites States (US) over the past decade. These programs have particularly emphasized investments in energy efficient appliances and enveloped improvements. They have generally required co-investment by residents and, as a result, have mostly reached medium to high-income residents, with low income residences, in effect, supporting the utility investments through higher energy costs. Additionally, utility initiatives directed toward behavior-based energy reduction have reached residences with more advanced technologies, such as smart meters and smart Wi-Fi thermostats linked to phone apps, technologies generally not present in low-income residences. This research seeks to inform development of behavior-based energy reduction programs aimed specifically at low-income residences, premised on peer-to-peer energy education and support. It focuses on the design and implementation of a pilot program for 84 low-income residences in a medium-sized Midwestern US urban neighborhood, followed by measurement of realized energy savings and assessment of program outcomes through surveys of resident participants and interviews with program implementers. Only 21 residences provided an initial response to outreach. Of these, only 11 participated, and of these, energy savings were, in general, modest. However, evidence based upon other research and qualitative data obtained from program implementers and participants is presented in this study for the development of an improved design. The improved design emphasizes grassroots community co-design of the program and community engagement through program implementation to transform energy consumption and behaviors and find energy justice for vulnerable communities.
\end{abstract}

Keywords: energy burden; peer-to-peer; energy behavior; energy justice; low-income; underserved communities; energy savings

\section{Introduction}

Research from the scientific community attests that climate change is a paramount concern in the contemporary world and has identified humankind as a primary catalyst of the rising risks. According to the Intergovernmental Panel on Climate Change's 2018 Special Report, global temperatures have risen approximately $1{ }^{\circ} \mathrm{C}$ from human activity since preindustrial times [1]. Modern society remains dependent on the production and consumption of substantial amounts of energy, and the energy sector plays a vital role in the everyday life of a large share of the global population as well as in the economy. The residential sector is responsible for a significant portion of energy consumed and the 
resulting greenhouse gases emitted; nearly $20 \%$ of the 5130 million metric tons of carbon dioxide emitted by the US in 2019 was from the residential sector [2]. The deleterious impacts from emissions are spatially uncontrollable, but vulnerable populations have been the most acutely affected [3,4]. Thus, the production, distribution, and consumption of energy is a global concern for environmental and social justice.

Energy justice looks at the energy sector from a social justice perspective to expand the scope of energy beyond economic and societal benefits. It analyzes and reveals the human costs of energy and the injustices that have resulted from the increased demand and reliance on energy [5]. The principle of energy justice has numerous definitions, but generally, the principle stems from the theories of distributive, procedural, and recognition justice [6]. According to Sovacool and Dworkin (2015), energy justice is defined as the following: "The right of all to access energy services, regardless of whether they are citizens of more or less developed economies. It encompasses how negative environmental and social impacts related to energy are distributed across space and time, including human rights abuses and the access that disenfranchised communities have or should have to remedies [5]".

There are two prominent ways in which distributive justice applies to energy justice: (1) the spatial and temporal location of energy infrastructure and access to energy, and (2) the benefits and costs that accompany the production, distribution, and consumption of energy. The procedural component of energy justice concerns energy policy and decisionmaking processes that are just and transparent such that individuals have equal input and are equally represented and considered. Lastly, energy justice includes recognition justice, which is the theory emphasizing the necessity of properly identifying all forms of injustice within the energy sector and, therefore, is essential for achieving procedural justice [5].

Energy insecurity and energy burdens are two types of injustices that exist in the energy sector. Energy insecurity refers to energy as an unstable and unreliable resource for vulnerable populations that are physically or financially disadvantaged $[4,7,8]$. According to the US Energy Information Administration's (EIA) Residential Energy Consumption 2015 Survey, out of a total of 118.2 million US households, 37 million were energy insecure, with 25.3 million reducing food purchases or forgoing the purchase of medicine to pay utility bills, 12.8 million living in unhealthy temperature living environments, and 17.2 million being disconnected from energy access [9].

In contrast to energy insecurity, energy burden pertains exclusively to financial inequality in energy, expanding beyond financial and physical inequalities and disadvantages. Specifically, energy burden is the percentage of a household's gross annual income spent on utility bills. This is a social injustice because underprivileged populations endure disproportionately high energy burdens when compared with their counterparts $[10,11]$. In the US, 25.8 million low income households experience an average energy burden of approximately $8.1 \%$, over 3.5 times greater than that of non-low-income households, whose energy burden is approximately $2.3 \%$ [11]. Furthermore, energy burdens are disproportionately higher for minorities and other marginalized populations. According to the American Council for an Energy-Efficient Economy's 2021 assessment of household energy burdens by Drehobl et al. in comparison with 1\% of non-low-income and $9 \%$ of non-Hispanic white households, $21 \%$ of black households experience severe energy burdens, which is defined as energy burdens where households spend at least three times more of their income on utility bills than median households [11]. The energy burdens endured by households are further exacerbated by unequal access to clean energy offerings [12].

Because energy insecurity and high energy burdens most severely impact financially disadvantaged populations and communities of color, the energy injustice these households face is oftentimes coupled with food and housing insecurity. In 2015, the EIA estimated that, of the aforementioned 25.3 million households that forwent food and medicine to pay utility bills, 7 million were faced with this decision on a monthly basis [9]. The aggregate of these injustices not only amplifies hardships but also contributes to and perpetuates intergenerational injustices in historically segregated and disenfranchised neighborhoods [4]. This can force households to live in uncomfortable, unsafe, stressful, 
and unhealthy conditions in order to pay their utility bills, ultimately increasing health risks and amplifying the burdens households endure $[4,8]$.

Energy behavior, defined as the habits, motivations, and values associated with energy consumption, is an important component of energy efficiency. However, it is often neglected and not a central focus of energy reduction initiatives. Incorporating energy behavior education and tactics into energy cost reduction programs can open the door to significant energy savings [13]. This will be exceptionally beneficial for low-income populations who are not able to make energy efficiency upgrades and repairs and who are not able to receive sufficient assistance from pre-existing programs. In a study conducted by Ouyang and Hokao (2009), residential occupants were provided education on a set of measures for the use of electric appliances to improve energy saving behaviors (e.g., refrigerating foods once they have cooled completely), and the study concluded that the adoption of energy saving behaviors has the potential to reduce energy consumption by nearly $14 \%$ in the residential sector [13]. The potential for savings among low-income populations, however, has not been well-documented. Nevertheless, it is certain that improved energy behavior has the potential to advance efforts toward an energy-just world through methods beyond energy efficiency and energy assistance programs alone.

\section{Background}

\subsection{Energy Poverty}

Energy poverty, commonly referred to as energy insecurity and fuel poverty, is a multidimensional facet of energy injustice that has gained increased attention by scholars and researchers $[7,14]$. Broadly defined as the deprivation of energy, energy poverty has numerous meanings based on the application, in which the reality of energy deprivation differs between and within developed and developing economies [8]. In 2017, nearly one billion people lacked access to energy globally [15]. Of this, an estimated $87 \%$ of the world population without electricity are in rural areas [16] and 200 million people in developed economies suffer from energy poverty [17]. Energy poverty is, thus, a complex concern that requires a comprehensive understanding of energy deprivation from a global, national, and local perspective.

Acknowledgement and action against energy poverty first began as the concept of fuel poverty in the United Kingdom (UK) in response to rising energy costs in the 1970s. The early theory of fuel poverty emphasized household incomes, high energy costs, and poor domestic energy efficiency as causes of energy deprivation and formally defined fuel poverty as households spending more than $10 \%$ of their income on energy $[8,10,17]$. Since then, the understanding of energy poverty has evolved and is also typically associated with lack of access to modern energy and unreliable energy services $[10,17]$. These understandings alone, however, fail to acknowledge vital components of the reality of energy poverty. Energy poverty cannot be misidentified and merely associated with general income poverty because it encapsulates more than being able to afford energy and includes external factors such as physical personal and infrastructural limitations, medical conditions, and social, economic, and political factors [4]. Furthermore, financial development, policy, infrastructure, food and housing insecurity, physical and mental health, institutional racism, etc. are critical characteristics that must also be considered when analyzing energy poverty $[7,8,18]$. Acknowledging this nexus of energy poverty and the aforementioned systems and injustices is essential as focus turns toward combating energy poverty.

In the US, there are two federally funded energy assistance programs that are intended to address these inequalities: The Low Income Home Energy Assistance Program (LIHEAP) and The Weatherization Assistance Program (WAP). LIHEAP is offered by the Office of Community Services through the Department of Health and Human Services, which serves to help low-income households meet their energy needs. Services offered through these programs include bill payment and energy crisis assistance, energy-related home repairs, and weatherization, which is the process of making improvements and upgrades to increase a home's energy efficiency and resistance to weather changes [19]. WAP is operated through 
the Department of Energy, offering eligible households weatherization improvements and upgrades to increase energy efficiency and, thus, reduce energy costs [20]. These programs aim to alleviate energy burdens, reduce utility bills for energy insecure homes, and improve the health and safety within a home.

There exists, however, a significant gap between the capacity of these programs and the need for assistance. According to Bednar and Reames (2020), LIHEAP provides assistance to approximately only $25 \%$ of eligible households per year, and out of nearly 40 million eligible households, WAP has only been able to weatherize 7 million households [10]. Barriers that prevent greater access to these programs include available funding, state level priorities, and the high demand for weatherization, which is much greater than the rate at which weatherization improvements can be implemented [4,11]. With the programs' focus primarily on momentary relief, they also do not provide sustainable solutions to eliminate energy poverty. In addition, if residents fail to pay their utility bills, they are required to pay back all energy assistance benefits they have received, thus, when eligible, low-income residents are often deterred from accepting energy assistance through LIHEAP. While LIHEAP was intended to be an emergency option for low-income residents, the reality is that residents enrolled in this program remain reliant on it in perpetuity. This assistance does not address the systemic conditions that result in high energy burdens and, with performance measures failing to measure long-term impacts, has not been shown to reduce the incidence of the non-payment of energy bills $[4,10,21]$. In contrast to energy bill assistance, weatherization and improved household energy efficiency has shown greater value in addressing energy poverty through energy cost savings, positive health and safety impacts, employment opportunities, and a foundation for continued energy efficiency upgrades [10] and has the potential of reducing energy burdens by $25 \%$ for low-income households [11]. Weatherization through WAP, however, is significantly underfunded in comparison to the allocated funding for energy bill assistance through LIHEAP ( $\$ 3$ billion USD compared to $\$ 0.4$ billion USD, respectively) [10], and at the current rate, weatherizing all eligible households through WAP will take an estimated 360 years [11].

It is evident that greater action is needed to address energy poverty both within the US and across the globe. Despite the intensifying concerns and impacts of climate change that has led to a greater global push for sustainable development, there has been a lack of recognition and response to energy poverty [10]. For instance, the United Nations' Sustainable Development Goal 7 sets to achieve universal access to affordable, reliable, sustainable, and modern energy by 2030; yet, in a 2018 report of 46 national reviews, there was little acknowledgement of energy poverty [16]. To shift this trend and increase response to energy poverty, it will be essential that action taken includes measures beyond income poverty and includes factors such as financial development, advancement of renewable energy systems, and the health impacts of the lack of energy access $[10,14,15]$. In a study conducted by Nguyen et. al., 2021, the relation between financial development and energy poverty was analyzed for 65 economies across the globe. The study concluded that to address energy poverty, low and lower-middle income economies should focus efforts on the development of the financial sector for market-based support and on government policy that supports renewable energy, whereas upper-middle income economies should emphasize policy and regulations on the financial sector that push for greater sustainable development [14]. Global action must be methodologically established to acknowledge the nuanced reality of energy poverty, such as the dichotomy between developing and developed economies.

To fight energy poverty, it is critical to expand the acknowledgement and understanding of its complex and multifaceted nature. Inadequate and lack of action stems from the non-recognition and disrespect of energy poverty, consequently suppressing it in political debate and action [7]. Steps must therefore be taken to confront stereotypes that generalize energy poverty based on certain characteristics and demographics, such as income, and that recognize energy access as a human right that is influenced by the design and implementation of policy and infrastructure $[7,8]$. While numerous factors of 
energy poverty are beyond the control of individual households, the present study takes a localized and household level approach in order to refute generalized notions about those experiencing financial and energy poverty. This study will contribute to existing literature by gaining perspectives and insight on energy poverty from a household level. Additionally, it will address energy poverty by increasing access to energy education and equipping households with information and resources to better understand and take control of their energy behaviors.

\subsection{Values and Motivation of Energy Consumption}

A fundamental step in understanding the extent to which individuals adopt environmentally conscious and energy saving behaviors is to first analyze values and motivations. Previous studies on residential energy consumption reveal an exhaustive list of factors that influence values and motivations associated with energy savings behaviors. Hence, the findings discussed in this study do not provide a definitive approach to understanding values and motivations but instead serve as a guide and basis of factors to be considered.

The intentions behind individual energy behaviors take numerous forms. Lindenberg and Steg (2007) propose that behaviors and actions are driven by goals and how such goals are framed [22]. This theory postulates three goal frames: gain, normative, and hedonic. Gain goal frames are driven by protection and advancement, normative goal frames are driven by what is proper and acceptable, and hedonic goal frames are driven by the desire to feel better at a given moment. When applying these to environmentally conscious behavior, it is suggested that hedonic goal frames impact behaviors the strongest.

Intentions and goals alone, however, do not provide enough context for understanding environmentally and energy conscious behavior. To analyze the gap between intent and action, additional factors such as education, skills, and demographics must also be considered. Hines et al., 1987, indicated that in order for positive intention to lead to environmentally conscious behavior, cognitive knowledge and skills are essential [23]. The most successful results were seen when individuals were not only aware of the problem and actions they could take, but when they were equipped with the skills to effectively and successfully act. Furthermore, when the desire and intent to act in an environmentally conscious manner was lacking, the ability to act was more likely impacted by situational factors such as economic and social constraints. According to a study completed by Poortinga et al., 2004, "attitudinal variables explained a mere $2 \%$ of variation in home energy use, the variation explained increased to $15 \%$ after taking into account several socio-demographic variables" [24]. This research, therefore, conveys the interconnected relationship between personal intention and desire, accessibility to knowledge and skills, and socio-demographics and the complexity of understanding and achieving environmentally conscious behaviors.

The sense of personal and social influence over environmentally conscious behaviors is a factor that must also be evaluated. In a meta-analysis completed by Hines et al., 1987, it was revealed that self-blame and internal locus of control tend to lead to and be associated with environmentally conscious behaviors [23]. By taking personal responsibility, individuals are able to see and acknowledge that their actions are effective and impactful. In addition to internal influence, when individuals are exposed to social norms that promote such environmentally conscious behavior, their likelihood to engage in such behavior increases further, and they are more apt to modify current behaviors.

A behavioral nudge is another method of cognitive behavioral change that has implications for energy behaviors. According to Thaler and Sunstein (2008), a nudge is "any aspect of the choice architecture that alters people's behavior in a predictable way without forbidding any options or significantly changing their economic incentives" [25] (p. 6). There are numerous forms of nudges in the context of behavioral change and, as described by Thaler and Sunstein, can take the form of social and emotional nudges when analyzed from an environmentally conscious perspective. In a study of 300 households in San Marcos, California, households were provided energy consumption data for their individual household and the average for their neighborhood average [25]. For half of the households, 
this information also included icons indicating whether their energy usage was socially acceptable or not (i.e., icons portraying happy or unhappy emotions, respectively). These households were provided a social and emotional nudge.

After receiving information merely on previous energy consumption, above-average energy consuming households decreased their energy usage and below-average energy consuming households increased their energy usage. However, the outcome was more advantageous for the households who also received an emotion-icon: above-average consuming households substantially decreased their energy usage and below-average consuming households did not increase their energy usage, in contrast to households who did not receive an emotion-icon. By utilizing feedback to make energy consumption tangible and connecting to emotions and societal values, this study shows the value in leveraging social and emotional nudges to promote energy conscious behavior [25]. However, limited research and literature exists on applying behavioral nudges in an environmental and energy saving context [26].

These research findings indicate the complex and dynamic nature of energy behavior that is dependent upon a multitude of factors. The aforementioned studies primarily focused on a range of demographics and are not indicative of how values and motivations may differ for low-income communities specifically. For instance, low socioeconomic status may have different needs or priorities and, in many cases, may be unable to act upon environmentally conscious and energy savings values. Nonetheless, these insights provide an understanding of how values and motivations are influenced by internal and external factors and how they shape energy behavior.

\subsection{Peer-to-Peer Education}

Peer-to-peer education is a method in which a representative, educator, mentor, or coach of a specified program is of the same or similar background as the participant [27]. This method has been implemented across a multitude of fields and demographics, but little to no research exists applying this method in underserved communities to modify energy behavior and decrease energy consumption.

The understanding behind the value of peer-to-peer methodology can be explained from a psychological standpoint. In a study analyzing the impact of peer teaching in medical education, psychologists suggest that the success of such teaching is linked to two factors: cognitive and social congruence [28]. From a cognitive perspective, learning takes place when new information is introduced to the brain and relationships and networks are established with pre-existing knowledge to adopt the new information. Cognitive congruence implies that an individual is more apt to introduce information to their peer by minimizing the gap between new and pre-existing knowledge. In addition, social congruence explains that peer-to-peer education is effective because peers are more vulnerable and less anxious with someone they relate to as compared to figures of authority and perceived superiority, ultimately increasing confidence and the ability to learn.

The efficacy of peer-to-peer education has been studied in fields such as health, nutrition, and education to analyze and validate the benefits of peer-to-peer indicated by these psychological explanations. In one study completed at the University of California, San Francisco, the impacts of peer education and coaching among low-income patients with diabetes were investigated $[29,30]$. Patients were recommended by clinicians to partake in training to become peer health coaches for patients with similar health backgrounds to determine if the role of a peer health coach would aid in the reduction of hemoglobin A1C ( $\mathrm{HbA1C}$ ) levels. While the retention of the peer health coaches decreased by over half from enrollment to the completion of the study, data from the training sessions revealed that $86.5 \%$ completed the training and $81.3 \%$ passed the final written and oral exams administered prior to health coaching. Among the patients who went through training, 28.1\% had graduated from college and 25\% had not completed high school [29]. Despite these factors, after six months of peer coaching, there was a significant reduction in $\mathrm{HbA1C}$ levels among patients receiving peer education support when compared with patients who did 
not participate [30]. This study revealed that lower socioeconomic status individuals can successfully acquire necessary knowledge and skills and serve as effective peer educators.

Furthermore, peer-to-peer research has been conducted in nutrition education in low-income communities. Developed by California's Public Health Department Nutrition Program, two programs, Head Start and Parents as Teachers, were created to increase the knowledge and improve behaviors and intentions for healthy and low-cost nutrition among low-income parents [31]. The programs consisted of two nutrition classes offered to parents that were taught by fellow parents. To measure the effectiveness of the program and of the peer education method implemented, questionnaires were administered prior to and after the completion of the classes to gather data regarding content of the class, as well as demographics. The results revealed that not only were parents overwhelmingly satisfied with the courses, but it also showed an increase in knowledge. According to the pre-class questionnaires, only $40.2 \%$ of participants were able to correctly identify low-fat foods, which increased to $95.1 \%$ correct identification post-class [31]. This program also revealed that optimal results were achieved when the peer-parent-teachers contributed to the structure of the program, which indicated an increase in commitment and personal investment. While the program did not study the long-term impact, it, nonetheless, confirmed that peer-to-peer education among low-income parents can successfully increase knowledge and intentions centered around healthy eating.

The use of peer-to-peer education and support has also played a prominent role among a multitude of services for low-income pregnant mothers. People's Equal Action and Community Effort Incorporated (PEACE) and Early Head Start (EHS) are federally funded services that serve pregnant women and families with young children in Onondaga County, New York, which, at the time of the study, had one of the highest infant mortality rates in the country [32]. In addition to home visits the program already provided, the Pregnancy Care Campaign (PCC) was created. This program revolved around a variety of events where participating expecting mothers were educated and motivated to live healthier pregnancies through interactions with professional educators and peer mothers. A primary goal of the PCC events was to allow the participating mothers to open up with other mothers in similar situations based upon the idea that "the knowledge of another person's experience helps inform one's own decision especially in making personal choices" [32]. One study of the campaign followed first-year participating mothers and found that there were no low-weight births or premature infants and that there was an increase in prenatal care among the mothers. Thus, this provides further confirmation on the role peer-to-peer education and mentoring can have among low-income communities and individuals.

The analysis of peer-to-peer based diabetes, nutrition, and pregnancy programs validates that peer-based behavior education can render change among low-income communities and individuals. The research posed here investigates if the same methodology can be used to realize significant energy cost savings through behavioral modifications, as there appears to be limited to no prior research investigating this application. Specifically, the present study outlines the development of a peer-to-peer energy reduction program for underserved communities, the preliminary results from a pilot program, and the knowledge gained during the pilot program for an improved program design, with the aim that these findings will amplify the impact of this program framework for future applications.

\section{Case}

\subsection{Case Study Overview: Pilot Peer-to-Peer Energy Reduction Program}

This project focuses on a pilot program conducted by a clean energy non-profit organization whose goal is to achieve energy and cost savings for low-income communities, specifically, in the Twin Towers neighborhood in East Dayton. At the time of the pilot program, Twin Towers was composed predominantly of members of white, black, Asian, Hispanic or Latin, and American Indian communities [33]. Many households within the neighborhood live in financial poverty with over $50 \%$ of all households and nearly $67 \%$ of female led households living in government defined poverty and approximately $65 \%$ of 
the families renting their home [34]. Between 2009 and 2013, 84 rent-to-purchase homes were built in Twin Towers to provide affordable housing as part of the Low-Income Tax Credit program, a tax credit for affordable housing directed toward low-income individuals in the US (Theoretically, the residents are eligible to purchase their home after a 15-year time period in which tax benefits can be obtained by equity investors. Having lived there for a long time, the residents would have accrued equity in the house, making purchase more feasible. However, a majority of the annual earnings of those living in the homes is less than $2 / 3$ of the median income and much of this housing is generally transient with few residents living in the houses for more than five years. Thus, homeownership is rarely attained).

The housing manager of the 84 homes required all residents to sign a utility release form for utility information to be obtained to understand the financial situation of each household. Through these releases and a partnership with the providing energy utility, monthly energy consumption data for each participating household were made available for this study. These 84 homes are similarly constructed three and four bedroom models with a floor area of 110 and $140 \mathrm{~m}^{2}$, respectively, built for affordability with relatively high energy efficiency characteristics [35]. The electrical energy consumption of the 84 residences should have been less than the national average (approximately 10,000 kWh/year [9]), given that the floor area of the residences was about a third less than the average US residence as well as the fact that the houses were insulated better than average and included only low energy lighting. However, this was not the case. The mean annual electrical energy consumption of all residences was $10,300 \mathrm{kWh}$, slightly above the national average. Moreover, there was wide variation in energy consumption. Average annual energy consumption ranged from $3600 \mathrm{kWh}$ /year to as high as $24,000 \mathrm{kWh} /$ year (standard deviation from the mean was $2614 \mathrm{kWh} /$ year). Given the consistency of the housing set, the wide variation in energy consumption is only explainable from energy use behavior differences.

The original goal for the clean energy non-profit was to make an initial investment and install Wi-Fi, smart Wi-Fi thermostats, and solar panels at no cost to the residents in the 84 homes. Through these investments, the intent was to reduce energy costs by an estimated $10 \%$ and $50 \%$ in the short-term and long-term, respectively. To achieve this, the non-profit would utilize smart Wi-Fi thermostat data, building energy and geometrical characteristics data, occupancy data, and energy and water consumption data to generate machine learning models predicting the monthly energy consumption. These models would provide continuous data needed to analyze energy efficiency and identify areas for improvement, along with estimates of the financial value of the investments. In addition to these measurable goals, the program would offer employment opportunities for community members through the role of a peer-to-peer (P2P) energy educator, the main source of communication with the community and participating residents. A final long-term goal was to hire and train community members to complete energy efficiency upgrades and installations. Thus, the program was designed to lighten the burden of high utility bills and provide employment opportunities for the respective community. A summary of characteristics and demographics of the pilot program can be found in Table 1.

\subsection{Pilot Program}

The present study investigates the role energy behavior has in promoting energy savings among low-income residents through a unique approach that utilizes peer-to-peer education. Through research and analysis of previous studies, an action plan for peer-topeer education was formulated, detailing outreach to the community to invite residents to participate, hiring and training a P2P energy educator, managing Wi-Fi and smart Wi-Fi thermostat installations, delivering energy education, and distributing feedback to participants.

To educate and enact energy saving behaviors, a P2P energy educator was hired and trained to work with participants in the pilot program. While this role is intended to be filled by an individual from within the community, the first P2P energy educator was not a 
resident in the Twin Towers neighborhood. Nonetheless, they had shared lived-experiences and a deep understanding of the lifestyle of those they would be working with. They also had valuable experience in community development, which was a driving factor as to why they were chosen to fill this position for the pilot program. The goal was that they would use their experiences to connect with participants and establish a firm foundation for the position to be assumed by community members in the future.

Table 1. Summary of Program Details.

\begin{tabular}{cc}
\hline Program Details & Description \\
\hline Neighborhood Location & Twin Towers neighborhood in Dayton, Ohio \\
\hline Financial support & Ohio Housing Finance Authority \\
\hline Residence type & Low-income rent-to-purchase housing \\
\hline Neighborhood median income & $\$ 32,542[33]$ \\
\hline Average household size & 7.8 People [33] \\
\hline Neighborhood racial demographics & White, Black, Asian, Hispanic or Latino, two or \\
more races, American Indian [33]
\end{tabular}

Responsibilities of the P2P energy educator included contacting residents interested in participating, installing the noted thermostats in homes, communicating and forging relationships with participants, and educating and collaborating with participants to achieve energy savings. In addition to the P2P energy educator, there was a technical undergraduate intern. This individual worked alongside the P2P energy educator to facilitate the installation of the smart Wi-Fi thermostats, assist with the energy education process, and be a technical resource for the households and P2P energy educator.

Once the program structure was developed and the P2P energy educator and technical intern positions were filled, the first step of implementation was to inform residents in the Twin Towers neighborhood about the program (Figure 1). The 84 rent-to-purchase homes were the focus of the pilot program because, as previously discussed, the homes were built with similar structural and energy efficient characteristics, yet there were significant discrepancies in annual energy consumption. Thus, there was opportunity for behaviorbased energy savings among these houses. To contact residents, program flyers were mailed to each resident with program details and a form to register. Additionally, the P2P energy educator and technical intern expanded their outreach by going door to door to familiarize residents with the program. Out of the 84 households, 21 initially signed up for the program, and, ultimately, 11 responded to follow-up communication and participated in the pilot program.

The P2P energy educator then followed-up with participating residents to introduce themselves and begin the process of installing Wi-Fi and smart Wi-Fi thermostats in each home. The Wi-Fi was to be installed and supported at no cost to residents. Several households, however, already had Wi-Fi, thus these households instead received a monthly gift card to a local grocery store to provide equal value to them. Before the P2P energy educator and technical intern began the energy education process, there was a period of approximately one month to collect baseline data for the purpose of comparing energy consumption before and after energy education. The baseline data included the historical energy consumption for the twelve months prior to the study. While baseline data was being collected through a partnership with the energy utility providing service to the residences, the $\mathrm{P} 2 \mathrm{P}$ energy educator maintained regular communication with participants to further establish relationships and trust and to check-in and trouble-shoot issues they experienced with their newly installed Wi-Fi and thermostats. 


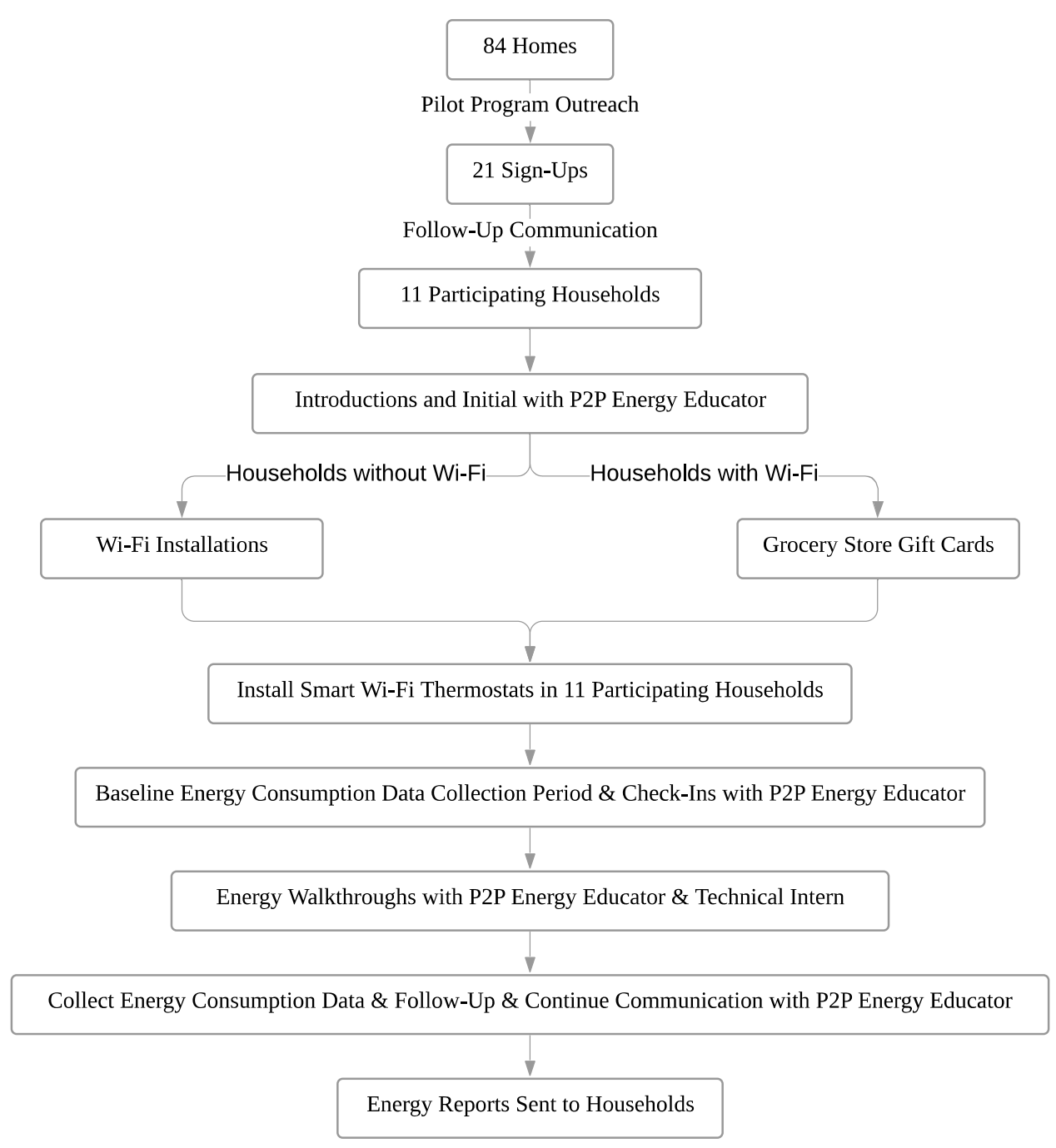

Figure 1. Pilot program process diagram: the pilot program began by conducting outreach to the 84 homes, which resulted in 21 initial sign-ups and 11 final participating households. Following initial introductions and communication with the P2P energy educator, Wi-Fi was installed in participating households that did not have Wi-Fi and grocery store gift cards were distributed to households with Wi-Fi already installed in order for smart Wi-Fi thermostats to be installed in the 11 participating households. There was then a short period in which baseline energy consumption data was collected when the P2P energy educator maintained frequent communication with participants. Energy walkthroughs were then completed with each household, and after further data collection and follow-up with the P2P energy educator, individualized energy reports were generated and sent to each participating household.

An energy walkthrough was then completed with each participating household after the baseline data collection period. In collaboration with the P2P energy educator, the technical intern prepared a checklist, informational handout, and energy consumption report, which were used as guides for the energy walkthrough. The checklist was composed of energy saving behaviors and practices categorized by room and type. It also included additional questions and points of discussion that were to be addressed during the energy walkthroughs. A comprehensive and condensed version of this checklist was created to serve as an informational handout for participants. To provide participants with insight into how their energy consumption compared to those in their community, a report was generated that documented each individual home's energy consumption as well as the maximum, minimum, and average energy consumed in their neighborhood. Ultimately, the goal of the energy walkthrough was to begin the energy education process 
by introducing ways to reduce energy consumption, helping participants become aware of energy consumption patterns, and gaining an understanding of each household's specific needs and capabilities.

The energy walkthrough was primarily led by the P2P energy educator with the technical intern present to answer technical questions and be an additional resource and reference for educating participants. During each walkthrough, the P2P energy educator went over the energy consumption report with the participants. The checklist was utilized to discuss their current energy consumption practices, issues or concerns they had about reducing energy, and to walk through the house with the participants identifying energy reduction practices in specific rooms and for specific tasks. Lastly, an informational handout was provided to be used as a reference for the individual(s) present during the walkthrough and for any additional members of the household.

The P2P energy educator followed a similar approach for each walkthrough but tailored the process as necessary to acknowledge specific needs and reactions of participants. For example, the heads of some households included their children in the walkthrough, thus the P2P energy educator and technical intern worked to engage the children during the visit. Following the energy walkthrough, the technical intern documented the interactions and discussions with each participating household. A critical element of this documentation was to take note of home repairs or issues that were of concern for the household or that were prohibiting a household from being able to adequately reduce their energy consumption.

Following the energy walkthrough, energy consumption data continued to be collected and analyzed for the participating households. To document changes and progress and provide the households with feedback, monthly energy reports were created. These reports presented monthly household and neighborhood energy and cost savings based upon the measured energy consumption and the weather-normalized energy consumption obtained through the machine learning model developed for each residence. The savings were then converted to metrics that would provide a better understanding of how the savings translate to everyday life. Some of these metrics included the equivalent number of phones charged, number of trees saved, gallons of gas, and number of meals based on the energy and cost savings. The energy reports also included a simple tip for additional ways residents could incorporate energy savings behaviors into their lives and homes.

Regular feedback was incorporated into the program as a means to further establish communication and relationships with participants, build community engagement, provide additional energy education, and encourage the process of energy behavior changes, as described by the transtheoretical model of behavior change [36]. The intent was to send energy reports to the participating households on a monthly basis. However, due to the timeline of the energy walkthroughs and logistical changes within the program, the energy reports were not consistently sent and discussed with participating households.

\subsection{Program Status at Completion of Pilot Program}

After energy reports were sent to participating households with feedback based upon their response and energy behavior changes following the energy walkthroughs, the pilot program was temporarily put on pause to re-evaluate and measure progress of the program. Additionally, this time was spent adapting to the unforeseeable restrictions from the COVID-19 pandemic. This allowed the program to be restructured and strengthened for a relaunch and more complete implementation of the program in the neighborhood. A new P2P energy educator was also hired during this time and completed training and preparation to work with the participating households. Currently, the energy reduction program is continuing to be implemented in the initial neighborhood.

\section{Methods}

This study takes a multi-method and interdisciplinary approach to assessing the processes and efficacy of the peer-to-peer pilot program. Methods of assessment include 
surveys of residents, collections of program notes, interviews with program leaders, and home energy use data tracking.

\subsection{Participant Survey}

Energy saving behaviors and behavior modifications are complex and dynamic in nature, and numerous studies and analyses unveil the psychological, physical, social, and situational facets of such complexities. However, limited research exists focusing on these topics solely within underserved and low-income communities. Surveys were, therefore, created and administered to participants in the pilot program to gain insight on participants' current energy usage trends, initial impressions of the program, and energy consumption values and motivations. Furthermore, survey data provides information on individual needs and interests of participants. This can be used to facilitate future interactions, tailor the program to particular households, and understand nuances on the views and realities of residential energy use within the neighborhood. According to Fredericks et al., 2015, environmentally conscious behavior and the ability to modify behavior is influenced by socio-demographics, situational factors, and phycological and personal values [37]. Thus, the survey was structured into three categories: demographics and general information, program experience, and values and motivations.

The portion of the survey evaluating the values and motivations of energy behavior was based on previous literature, which highlights the numerous factors that are associated with and influence behavior change and environmentally conscious actions. Consequently, values and motivations must be analyzed from a holistic viewpoint that does not isolate single factors but instead examines the interconnected nature of all factors. These findings, therefore, were used as a guideline for the types of questions and topics to include in the participant survey when investigating energy behavior and the connection to personal values and motivations.

The survey design was based upon a survey methodology employed by Carrus et al., 2008, in a study conducted to evaluate recycling and public transportation behaviors [38]. Because this study analyzed similar overarching topics associated with environmental and behavioral actions, the original questions were tailored using the above findings for the purpose of this study.

Generating the survey for participants not only required research into the content of the questions but also careful consideration for how the survey was structured. The survey included various types of questions such as rankings, agree or disagree, multiple choice, and free response. Each question was carefully analyzed to evaluate the question format to utilize, the proper language to use, and where to include the question within the survey. These considerations were taken to prevent discrepancies between participants' understanding of questions and to prevent responses from being influenced by the organization and framework of the survey.

Surveys were administered to participating households during the energy walkthrough with the P2P energy educator and technical intern. For completing the surveys, households were incentivized with a gift card to a local grocery store. In total, eight surveys were completed and analyzed for this study.

\subsection{Interviews}

To analyze the internal processes, experiences, and takeaways of the pilot program, interviews were conducted with key figures involved in the program's development, implementation, and advancement. All interviews were held remotely via video conference. Each interviewee was asked a series of the same general questions as well as individualized questions based upon the nature of the work they completed and their contributions to the program.

Interviews were conducted to examine the perspectives and experiences of internal sources from each angle of the program. With certain individuals working on the technical and program logistics and others working on community development directly with the 
residents, these interviews would determine nuances between the experiences and views of each individual and trends among their responses. The ultimate purpose was to inform which characteristics of the implemented program needed to be reevaluated and reanalyzed and to help envision needed processes for future advancement of the program in the local context associated with this research and elsewhere.

The individuals chosen to be interviewed for this study occupied different positions in the pilot program and were involved in various stages of its development, implementation, and advancement. A total of five individuals were interviewed for this study. This included the (1) P2P Energy Educator, (2) Technical Intern, (3) Nonprofit Director, (4) Program Innovator and Energy Analyst, and (5) Program Coordinator. Brief descriptions of each interviewee with their respective role and contributions in the program can be found in Table 2. Additionally, for the pilot program, the positions of the P2P energy educator and technical intern also included assisting with the development and logistics of implementing the program.

Table 2. Descriptions of Interviewees' Roles.

\begin{tabular}{|c|c|}
\hline Position & Description (Roles, Responsibilities, and Contributions) \\
\hline P2P Energy Educator & $\begin{array}{l}\text { Responsible for interactions with residents and was the point of contact between the } \\
\text { participating households and the rest of the program; served as a mentor and peer to the } \\
\text { residents and provided education on energy saving behaviors and tools; responsible for } \\
\text { relationship building with residents; established initial communication with households who } \\
\text { signed up for the program; scheduled meetings for thermostat installations, energy } \\
\text { walkthroughs, and all other interactions; assisted with thermostat installation; and maintained } \\
\text { regular communication with residents to follow-up on meetings and address questions. }\end{array}$ \\
\hline Technical Intern & $\begin{array}{l}\text { Worked closely with the P2P energy educator interacting with households but with a greater } \\
\text { focus and background on the technical aspects of energy savings; assisted with initial } \\
\text { outreach and thermostat installations; created preparatory materials and documents for } \\
\text { household interactions and energy walkthroughs; and kept track of technical related issues } \\
\text { and concerns from interactions. }\end{array}$ \\
\hline Nonprofit Director & $\begin{array}{l}\text { Focused on determining and navigating the role of the energy reduction program within the } \\
\text { overall purpose of the nonprofit; sought to create partnerships and make connections with } \\
\text { other community organizations to further the work of the program; primary fund-raiser for } \\
\text { the non-profit; and managed the budget. }\end{array}$ \\
\hline $\begin{array}{c}\text { Program Innovator and Energy } \\
\text { Analyst }\end{array}$ & $\begin{array}{l}\text { Collected historical energy data on residences, identifying the opportunity to realize } \\
\text { behavior-based savings; responsible for the ideation of the program with the intent to build } \\
\text { capacity within the neighborhood; introduced and proposed this program to the nonprofit } \\
\text { director and was the primary figure in the development of the program and the early stages } \\
\text { of partnership development; worked with utilities to collect energy data for participating } \\
\text { residences; and responsible for the measurement of savings realized for each residence and } \\
\text { collectively. }\end{array}$ \\
\hline Program Coordinator & $\begin{array}{l}\text { Community partner who worked for the nonprofit, managing numerous programs and } \\
\text { initiatives; began working with the program near the end of implementation of the pilot } \\
\text { program and transitioned into the role of overseeing the program; restructured the program } \\
\text { and prepared for a new P2P energy educator after the initial pilot program; and focused on } \\
\text { story development of the nonprofit and program to increase presence and awareness within } \\
\text { the neighborhood. }\end{array}$ \\
\hline
\end{tabular}

\subsection{Tracking Energy Consumption and Measurement of Savings}

To measure energy consumption changes as a result of actions taken during the program, access to the monthly energy consumption data of residents was essential. All participants were first asked and agreed to sign release forms guaranteeing confidentiality and permitting researcher access to their monthly energy consumption data. Researchers then worked collaboratively with the energy retailer responsible for the monthly residential billing to receive monthly energy statements and energy consumption for the twelve months prior to initiating outreach for participating residents. 
The energy characteristics of all houses in the study were obtained from reviews of the blueprints of all houses. Insulation values in metric units for the walls and ceilings were respectively RSI 3.17 and RSI 6.34. All windows were double-paned. The heating systems were all gas-condensing furnaces, with efficiencies of 0.95. All air conditioners were associated with SEER values of 14 . The only difference between houses were the floor areas, with residences having one of two values $\left(110\right.$ or $\left.140 \mathrm{~m}^{2}\right)$.

Weather data for each energy consumption meter period, including the twelve months prior to beginning the study, was obtained from the NOAA's Climate Data Online resource [39]. Collectively this data was used to build baseline energy models for each residence to predict energy consumption for any energy consumption meter period given the weather conditions present during that meter period. The approach employed by Al Tarhuni et al. [40] and Alinezi et al. [41] was utilized to develop these models, which effectively permit prediction of the monthly energy consumption based upon resident energy use patterns present prior to the start of the program. Fundamentally, this approach synchronizes monthly energy consumption data with local outdoor weather data (obtained from the NOAA Climate Data Online resource [39]). For each meter period, average outdoor temperature and probability densities for the outdoor temperature falling within the 60 uniformly spaced temperature bins ranging from outdoor temperature bins ranging from -23.33 to $37.78^{\circ} \mathrm{C}$ were used. A machine-learning algorithm based upon a stacked ensemble approach [41] was used to develop a model to predict monthly energy consumption for each residence based upon the energy consumption prior to the study. This model, when applied to post-program energy consumption data, enables prediction of the energy consumption based upon pre-program behaviors. The difference between the predicted consumption from the model and actual consumption for each meter period describes the change in consumption as a result of program actions.

Post initiation of the program, residence energy consumption changes for each meter period were estimated utilizing the energy model to predict energy consumption. This prediction was compared with the actual consumption. If the actual consumption was less than the predicted consumption, energy savings were inferred, whereas if this consumption was more than predicted, energy increases were inferred.

\section{Results}

\subsection{Participant Survey}

The survey results showed that out of the eight surveys completed, seven residents were aware of the Percentage of Income Payment Plan (PIPP) Program, an energy assistance program, two were enrolled in PIPP, and three were interested in learning more, as shown in Figure 2a. Additionally, when asked to indicate current energy saving behaviors, the surveys revealed that many households were aware of and engaged in energy saving behaviors in more than one way. This is revealed in Figure $2 b$ in which lighting, heating and cooling, and washing and drying clothes all were marked by six or more households as ways they were already attempting to reduce energy consumption. Finally, Figure 2c shows that motivators for adjusting thermostats vary in importance but implies that personal and family comfort influences thermostat adjustments the greatest.

It is vital to note that due to the limited reach of the pilot program and small number of responses, generalizable conclusions cannot adequately be drawn from the presented results. Rather, the responses serve as a means to further understand the implementation, development, and evolution of the program and to consider needs and characteristics of the neighborhood and households that otherwise may not have been observed. 


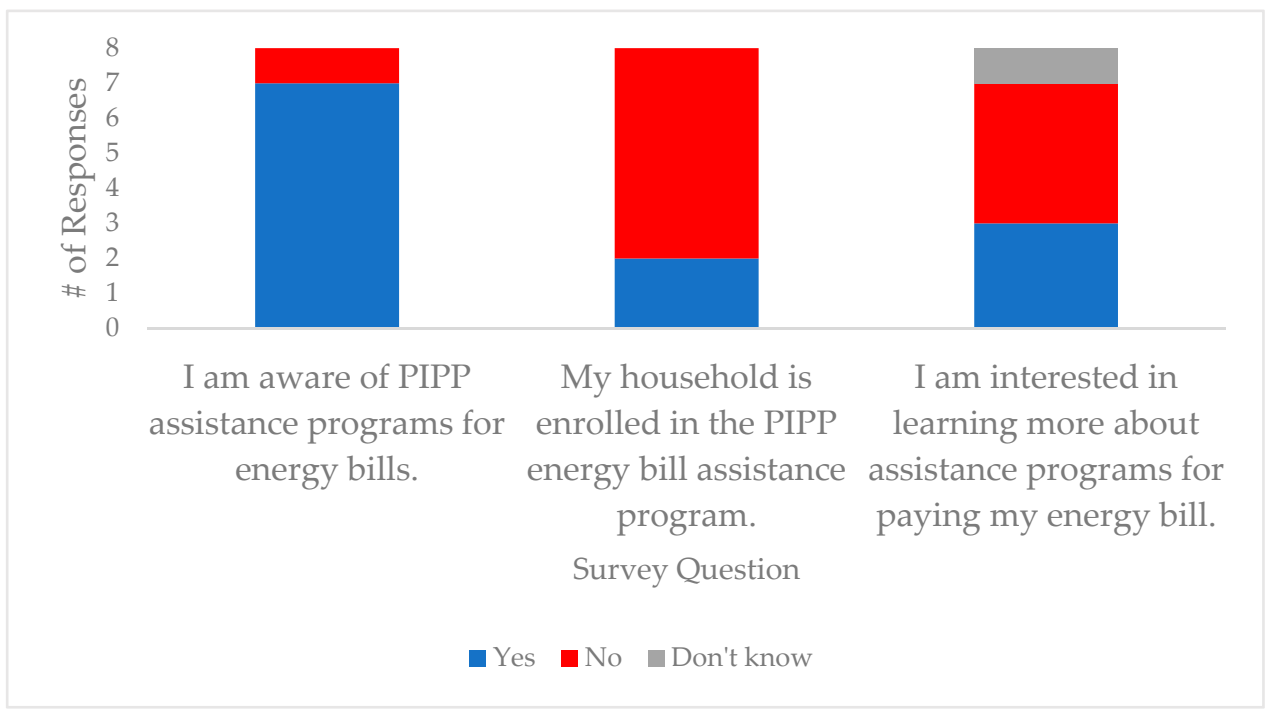

(a)

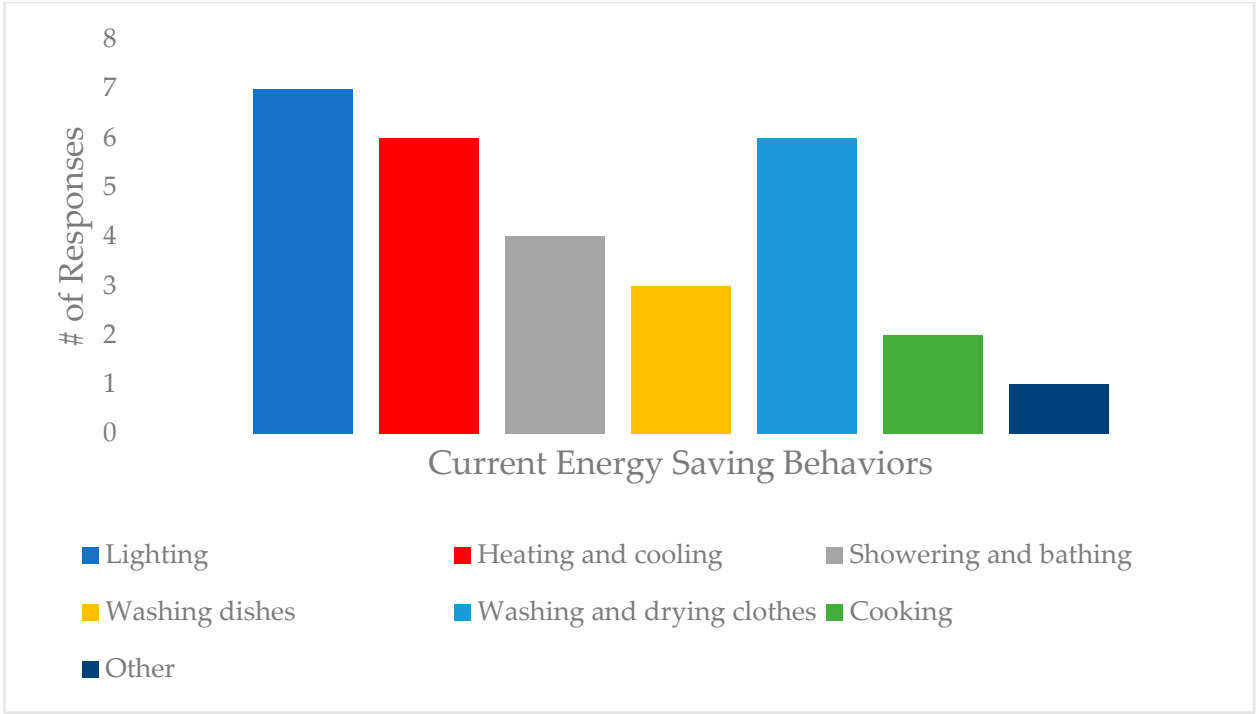

(b)

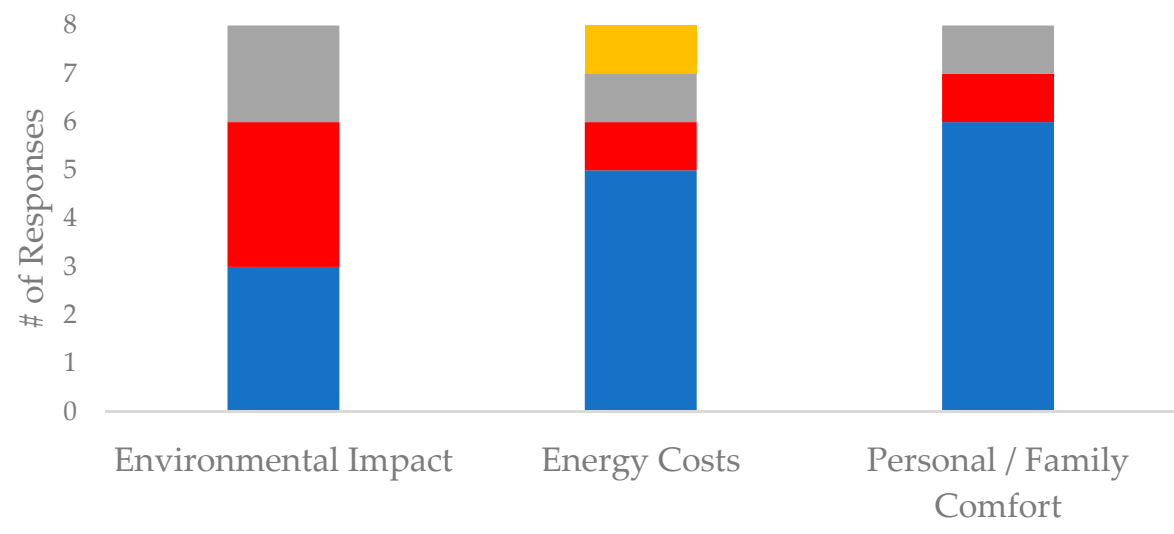

Decision Factors for Adjusting Thermostat

- Very Important

- Important

— Somewhat Important

Not Very Important

(c)

Figure 2. Participant survey results: (a) energy assistance programs; (b) energy behaviors; (c) thermostat motivators. 


\subsection{Interviews}

Upon completion of interviews with program organizers and coordinators, an analysis was conducted to examine responses. Five key areas and trends of takeaways, recommendations, and insight into the future of the program were identified through this analysis: (1) community empowerment and sense of control, (2) education and training, (3) program impact and reach, (4) program requirements and logistics, and (5) program as integrative and collaborative.

\subsubsection{Community Empowerment and Sense of Control}

Each interviewee was asked to describe their experiences and views on the success of the program. Their responses were derived from the limited results and evolution of the program beyond the initial pilot program. A common theme among the responses highlighted that residents were able to acquire a new sense of control and empowerment. According to the P2P energy educator, a successful aspect of the program was "having people understand they could take control of their utility bills by reading and understanding them." By learning about the relationship between behaviors and utility bills, residents were able to see that they could take control of their utility bills. This not only increased their sense of control in their understanding of their utility bills but also showed them their role in addressing climate change as well as how they could take control of aspects of their lives beyond energy consumption in what seemed to be simple and trivial ways. As explained by the program coordinator, "people understand they have more control in simple things in their lives than they think" and many do not know they can save money based on their thermostat, which then translates into curiosity of how and where else they can save money. The pilot program empowered residents to see their actions and behaviors as a way to gain control of their utility bills and other areas of their lives. Thus, the lives of participating households were impacted beyond energy and the primary scope of the program.

\subsubsection{Education and Training}

The responses provided by the interviewees brought forth the crucial role of the education and training required by individuals working in the program and the areas in the pilot program where education and training needs were insufficiently met. From a general and program-wide outlook, more intentional training and knowledge was needed for individuals in the program, particularly for the P2P energy educator and technical intern. There were two primary areas in which further training was necessary. First, greater attention was needed on technical knowledge such as utilities, utilities bills, energy programs, and miscellaneous specifics on energy consumption and savings. Second, the P2P energy educator and technical intern expressed a lack of training and preparation on soft skills for their specific roles as well as the program as a whole. Such training and skills included communication and people skills necessary for working with individuals with different levels of technical expertise within the program and also the knowledge of how to properly and consciously communicate with community residents and understand appropriate language to use. Furthermore, the interviewee's responses indicated a goal to strengthen the opportunity to provide education to residents on utilities, utility bills, energy programs, etc., which is dependent upon the knowledge and education of those in the program.

With the P2P energy educator being the primary point of contact and the person in charge of conveying information and education materials to residents, there were specific details identified of what education and training is essential for this role. According to the P2P energy educator, they did not feel adequately prepared to confidently and comfortably work and interact with fellow program developers and with residents. They suggested greater collaboration and education from program directors to feel more confident working with those in technical roles such as engineers and energy analysts. While the P2P energy educator's role is to be a peer and mentor to residents in the program, it is vital for them to gain an in-depth understanding of the technical components of the program 
in order to increase self-confidence and amplify their impact when working with residents. As the P2P energy educator stated, "They're counting on me to know something ... I should have answers." This includes the technical knowledge as previously indicated and knowledge of other community programs and organizations, both energy and non-energy related. Discussing energy with residents revealed insight into why certain households have high energy consumption, thus the P2P energy educator should be able to provide knowledgeable recommendations and assistance such as how to get mattresses or warm clothing if that is prohibiting a household's ability to turn down their thermostat and reduce energy consumption.

\subsubsection{Program Impact and Reach}

Another common trend among responses was an understanding of the impact the program had within individual households and within the community at large. A predominant takeaway was the need to include all household members in the energy education process. While conclusive energy consumption changes and savings were not able to be made based on the limited time frame of the program, as well as complications stemming from the COVID-19 pandemic, this understanding was significantly driven by the fact that the household whose energy consumption decreased substantially after the energy walkthrough had all household members present during the walkthrough.

This was further highlighted by the feedback the P2P energy educator and the technical intern received from residents during the energy walkthroughs. The feedback they received revealed that, while residents were receptive to a majority of the tips on ways to save energy in their homes, there were limitations and challenges in maximizing the impact and energy savings. For instance, the technical intern expressed that many residents appeared to believe they lacked the power and ability to save energy if they felt certain energy use was out of their control. Similar sentiments were echoed by the P2P energy educator, stating, "The houses were not our variables ... but in some ways, the houses were dramatically different ... a lot was (blamed on) the insulation of the house (which actually was the same for all houses) or (their) kids for the usage." These insights, therefore, reveal the necessity of incorporating the entire household in the energy education process as well as other obstacles homeowners face to realize the impact of their actions and barriers that inhibit the savings they are able to achieve.

To reach the entire household it was also clearly expressed that the approach must carefully consider how information is conveyed to the adults and children within households. According to the P2P energy educator, they were sometimes intimidated and concerned they would come across as arrogant when discussing energy savings tips with adults because energy savings is inherently tied to one's finances and, therefore, can be a sensitive topic. Ultimately, positively impacting a resident's energy savings behavior is complex, and best practices need to include entire households in the process and the aforementioned concerns that were revealed by the interviewees.

In addition to addressing the impact of the program on the household level, analyzing the impact on the community level was a critical factor that influenced the program's impact. As the program and energy education process began, it was quickly recognized that the time required to develop relationships and trust within the community is longer than initially anticipated. According to the nonprofit director, "We learned early on that the approach is too simple. The idea that you could establish trust with a group, a new community interface for them, and begin to change their behavior quickly was an incorrect assumption." Similarly, the program innovator and energy analyst said, "I had actually seen this initiative as being an example of how to combat climate change nationally with speed ... and I think the greatest learning and impact that I've had is that it is slow and about developing relationships over the long term." It is evident that the program must first establish relationships and trust within the community to enable connections with households on an individual level, which takes time and must be a long-term endeavor. This must include not only relationships with community members but also with community organizations and programs already 
working in the community. Thereby, the program and P2P energy educator can leverage the community's assets to collaborate and work with the community to assist in meeting the needs of the community and households. It is critical that the program and all partners acknowledge the amount of time required to establish relationships and that they have the bandwidth to accomplish this.

Based upon the interview responses, a significant component of establishing relationships is improving the presence and familiarity of the program in the community, something that lacked in the initial implementation of the pilot program. According to the program innovator and energy analyst, "I guess I just didn't initially realize it would just be so challenging to get people to sign up ... . we realized that step one has to be the establishment of relationships with community members in order to potentially establish trust." This response not only reiterated the aforementioned requisite for relationships and trust but provides further insight into gaining interest in the program from the community. The interviews revealed that the program needed greater community involvement and exposure from the beginning. It was suggested that in order to achieve this, the community must be part of this process to increase trust and familiarity and to ensure the program is driven by the community.

Lastly, the ability for this program to make a positive impact requires an in-depth understanding of the community. As indicated by the program coordinator, "This work needs to build to much greater system change, to energy democracy, and to what it means to actually be in charge of your neighborhood and its health and vitality ... It's pretty unfortunate how much we didn't know." Through the interactions with the community, the reality of the systemic issues and unnecessary dependencies the community endured became apparent. Particularly, simple things that may not typically be questioned or considered must be part of the process. Thus, while maintaining the goal of reducing energy consumption, the program and those involved must have a broad and in-depth understanding of the perspectives and experiences of the community beyond energy and energy savings alone.

\subsubsection{Program Requirements and Logistics}

Mutual recommendations, perspectives, and critiques of the requirements and logistics of the program were also revealed through the interviews. A particular need that was identified was the need for reliable funding and financial support. According to the program innovator and energy analyst, "We just realized that it is going to take time, and we've got to figure out a funding resource to help make that time feasible in the end." Thus, as a deeper understanding of the length of time required to establish community relationships and trust was acquired, it became evident that a greater funding source would be needed to create long-term and lasting community presence.

One element of the program that requires funding is the incentives residents receive for their participation. However, it was revealed that if these incentives continue in the future, they must be more intentional. This was clearly articulated by the P2P energy educator and their interactions with residents "I do believe that incentives work. I think that we could have done different things with the money that would have helped better if we were looking at it more individualized because we were looking at a broad spectrum... every single person that we're working with is dealing with different reasons why their bills are the way they are." To meet the goals of the program and make the long-term presence financially viable, it is suggested that incentives be utilized in a more purposeful manner that further aligns with the needs of the program and the individual situations of the residents. Fundamentally, if financial incentives are offered, they must reward energy savings and serve individual household needs.

It was also revealed that a more detailed plan must be established for the implementation of the program. Based on the responses from the interviews, it is critical to have short-term and long-term plans that emphasize both the technical and conceptual elements of the program and that also are built on the understanding of what sustainability means to the community. According to the program coordinator, "We need to know what 
it [sustainability] means to them based on their language and how they live on a day-to-day basis and adapt how we think it should be implemented in their neighborhood." Therefore, the program must balance the focus on the program specific goals of energy savings and on taking a holistic approach of what is needed to achieve community sustainability and resilience beyond energy. This implies that boundaries must be set on how far the program, as well as the role of the P2P energy educator, can veer off focus. Ultimately, for households to achieve energy savings, there are additional factors necessary to be acknowledged and included in the work.

Furthermore, the interviewees discussed the necessity to consider all angles of the program, of the community, and of any potential issues that may arise before beginning the implementation process. In order to implement this, the program plans must not overlook simple characteristics and understandings of the community and require significant communication and collaboration with all individuals involved in the program and with community members. Finally, it was indicated that in order to meet these requirements and account for the details necessary for the implementation of the program, it is vital that plans established are adaptable and have the ability to evolve as new needs and understandings are discovered.

\subsubsection{Program as Integrative and Collaborative}

A final trend revealed through the interview responses is the necessity of the program being integrative and collaborative, which, while discussed in previous sections, deserves further emphasis and detail. To maximize community presence and build relationships and trust, feedback from the interviewees strongly suggested to not only establish partnerships with existing organizations already operating within the neighborhood, but to also implement this program into the work of an existing organization already trusted, rooted in, and represented by the community. By having the program under the umbrella of such an organization with well-established community presence and partnership, the time and work required to build new, long-term relationships and trust will be mitigated.

Other recommendations for taking a more collaborative approach included having the community identify a P2P energy educator, creating opportunities for youth and high school students to get involved, and having the outreach and presence of the program be completed by community members themselves. According to the program innovator and energy analyst, "I would also encourage the community to identify a peer-to-peer person whom they would want to hire to manage the program, and we would actually manage the program through that organization ... it would be transparent; they would be seen as the enablers of their community." The initial belief was that the pilot program addressed the need of community engagement by having a P2P energy educator with similar experiences and by incorporating the program into the work of a nonprofit. However, these sentiments reveal the depth at which this must be implemented and indicate the recommendation of redirecting practices within the program to be driven and operated by the community itself.

Finally, insight from the individuals involved in the development and implementation of the program highlighted the potential for the program to serve as an opportunity for broader community development and work beyond energy savings. According to the program coordinator, "It just starts the conversation for future work that is much bigger than just saving a few dollars in your home. Like, what is it going to be [to build] a truly sustainable and resilient self-sufficient neighborhood." Thus, future programs should not focus on energy and energy cost savings alone but should, instead, integrate with other goals and needs of the community and community organizations. This was further emphasized by the idea that the program can provide the impetus to create greater system change and advance the efforts underway to achieve community resilience.

\subsection{Preliminary Home Energy Usage Result}

Comparisons of the household energy usage summed over the three month period following the energy walkthroughs and the monthly energy savings are shown in Figure 3a,b. 
Out of the eight households included in the analysis, three showed energy savings and the remaining five showed increases in energy usage. For each month of energy data collected in 2020, the household averages were 760,630 , and $665 \mathrm{kWh}$ respectively, slightly greater than averages for 2019 energy data. Analyzing the energy savings for each house during each month of available energy data, there was a maximum energy reduction of $53.17 \%$ and a maximum energy increase of $88.76 \%$.

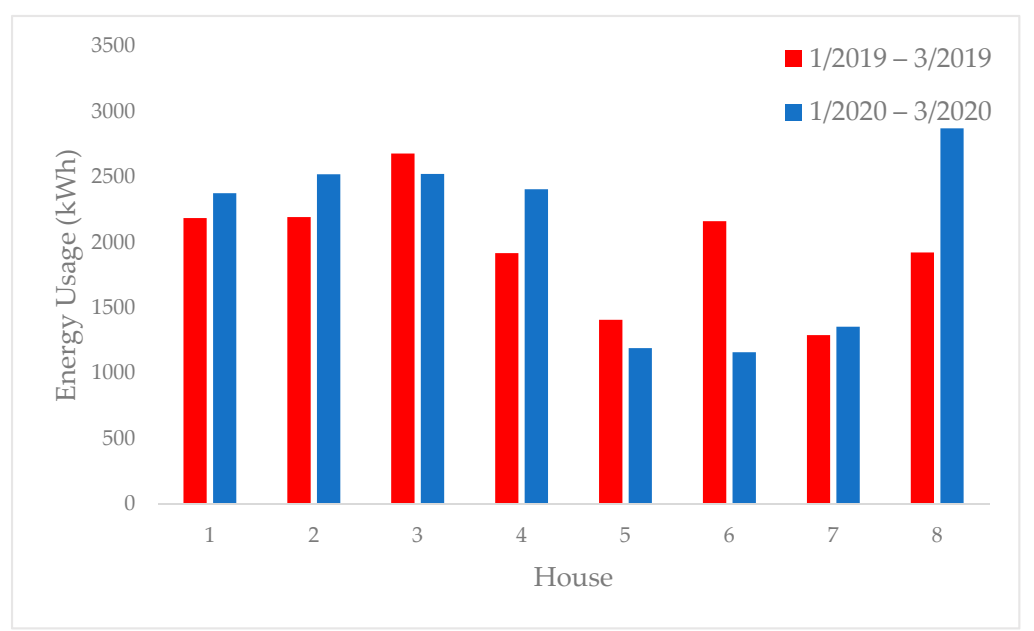

(a)

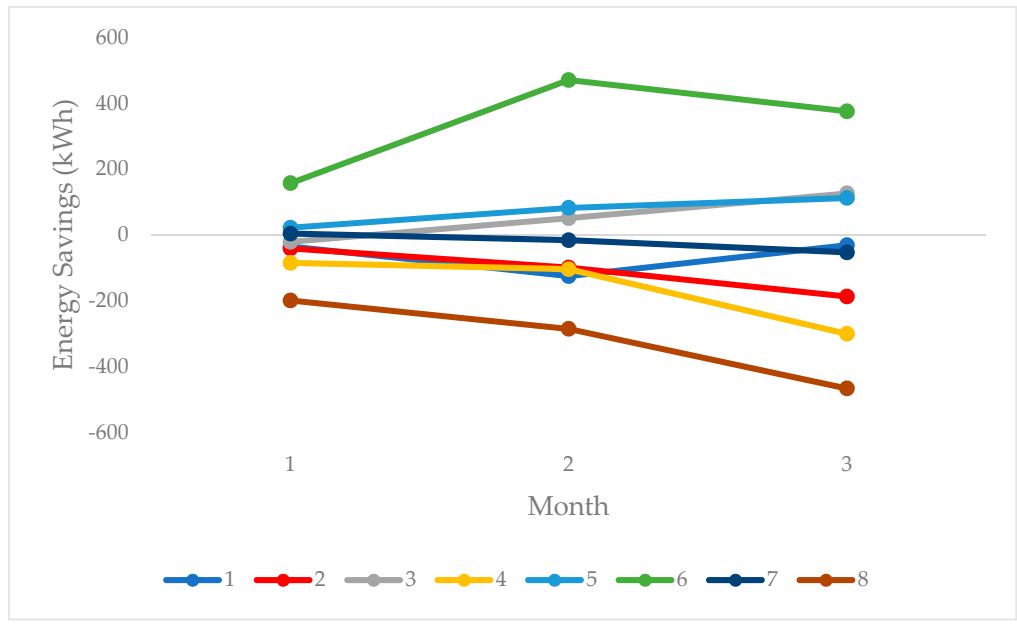

(b)

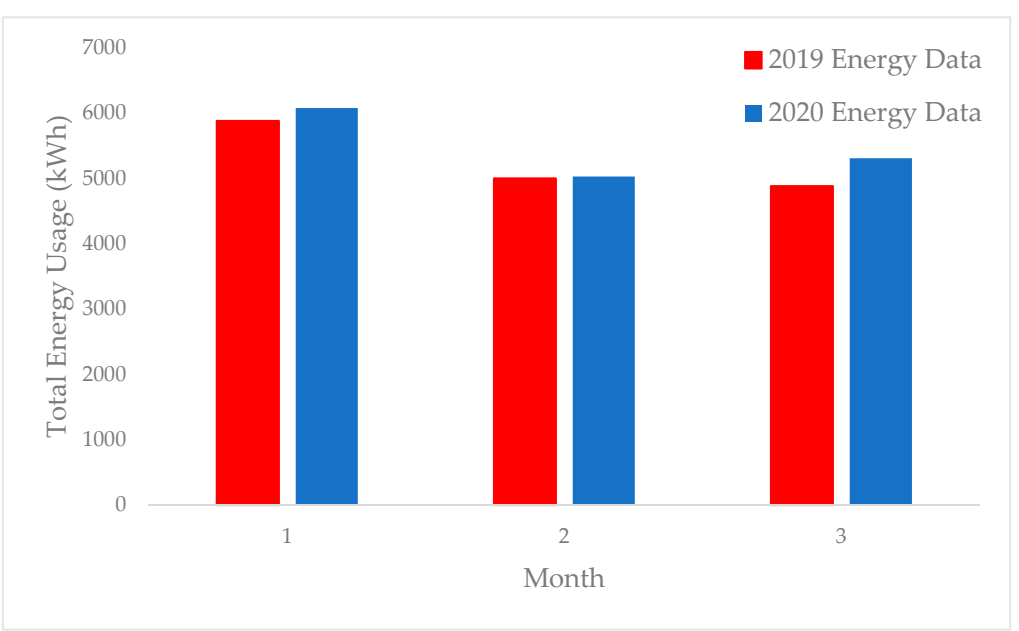

(c)

Figure 3. (a) Total household energy usage for 3-month period; (b) household energy savings (3-month period post-energy walkthrough); (c) total energy usage, 2019 and 2020 comparison. 
Summing the energy usage of all participating households, energy changes between 2019 and 2020 were less appreciable, as shown in Figure 3c. Overall, the participating households experienced an energy increase of $4.11 \%$ over the three-month period from 2019 to 2020. However, this amount is within the uncertainty of predicting energy consumption and savings. This equated to a total energy increase of $648 \mathrm{kWh}$, equivalent to a cost of $\$ 76.40$ and 0.46 metric tons of $\mathrm{CO}_{2}$ emissions (Table 3). As evident in Figure 3a, one household, house 8 , was an outlier in terms of the extent of energy increase with a total increase of nearly $950 \mathrm{kWh}$, negating all energy reduction achieved by other households. Furthermore, the aggregate energy consumption reveals the greatest energy increase was seen during the third and final month included in the analysis.

Table 3. Household savings (total for 3-month period).

\begin{tabular}{cccc}
\hline House & Energy (kWh) & Cost (\$) ${ }^{\mathbf{1}}$ & CO $_{\mathbf{2}} \mathbf{( M e t r i c ~ T o n ) ~}^{\mathbf{2}}$ \\
\hline 1 & -191 & $-\$ 22.52$ & -0.14 \\
2 & -327 & $-\$ 38.55$ & -0.23 \\
3 & 156 & $\$ 18.39$ & 0.11 \\
4 & -489 & $-\$ 57.65$ & -0.35 \\
5 & 216 & $\$ 25.47$ & 0.15 \\
6 & 1002 & $\$ 118.14$ & 0.71 \\
7 & -65 & $-\$ 7.66$ & -0.05 \\
8 & -950 & $-\$ 112.01$ & -0.67 \\
\hline Average & -81 & $-\$ 9.55$ & -0.06 \\
Total & -648 & $-\$ 76.40$ & -0.46 \\
\hline
\end{tabular}

${ }^{1}$ Energy costs of $\$ 0.1179 / \mathrm{kWh}$ for Dayton, Ohio [42]. ${ }^{2} 7.07 \times 10^{-4}$ metric tons $\mathrm{CO}_{2} / \mathrm{kWh}[43]$.

\section{Discussion and Improved Program Design}

With participation of 11 out of a potential 84 homes, qualitative and conclusive outcomes cannot be made. Rather the presented results serve as a means to improve the design of an energy reduction program for low-income communities that utilizes peerto-peer education and focuses on energy saving behaviors. In the improved program design, existing literature and anecdotal evidence from the pilot program are leveraged to emphasize the critical role of community engagement. The following discussion highlights key insights, considerations, and improvements on how this program can be strengthened and improved as it evolves and is scaled and expanded beyond the initial neighborhood.

\subsection{Maximizing Program Impact}

A primary takeaway from the interview responses, which was confirmed based on the results of the participant survey and energy data, was the need to improve the impact of the program on a community and household level. While the need to establish community relationships and trust was known to be a challenge and essential component of the program from the beginning, the time required and the steps necessary to achieve strong and impactful relationships was underestimated. Establishing a robust presence in the neighborhood is, thus, a vital component that should be the focus of the program before beginning energy education on a household level.

In addition, the importance of providing energy behavior education to all members within a household was revealed. This was shown to anecdotally influence the ability for households to achieve energy savings and is supported by the results of the participant surveys, interview responses, and energy data. Although the available data and responses are limited, household members indicated that the ability to modify energy use habits in their household was more easily attainable for themselves and more difficult for others within their household. However, the available data and responses are limited, and further research is needed. Moving forward, a goal of educating households on energy savings behaviors should emphasize collaboration among all household members in a manner 
that acknowledges the complexity of and accounts for the diversity among household compositions and roles of household members within low-income communities.

\subsection{Understanding Program Reach}

Preliminary results revealed gaps in the ability to accurately understand and analyze the available yet limited data. One significant challenge the program faced from the onset of the program was gaining interest within the community for households to sign-up and participate-limiting the reach of the program and ability to properly evaluate results.

With 11 participating households out of the 84 households in the neighborhood who were contacted and informed about the program, it was uncertain as to what appealed to those 11 households and what barriers existed that hindered greater interest. While mail-in flyers were sent to each household and additional door-to-door outreach was conducted in an effort to increase community presence and interest, the limited participation clearly demonstrated the lack of community engagement and need to gain community buy-in and involvement from the inception of the program. As previously discussed, strong presence and trust are indicators for gaining interest and engagement. Evaluation of survey and interview responses and energy data also revealed further insight into potential factors that should be explored further in the future. Based upon the participant survey results on utility bill costs and assistance programs, the indicated energy burdens endured by participating households were not as high as initially anticipated. This raises the question as to whether energy burdens are not exceptionally severe in the particular neighborhood or if among all the households in the neighborhood, those with less severe energy burdens were those who opted in to participate in the program. It is possible that households with the most severe energy burdens did not have the bandwidth to participate and that the challenges and realities of living in financial poverty limited participation. This question requires further attention in future research.

The reality and uncertainties of living in financial poverty revealed considerations necessary for properly analyzing energy consumption and understanding the capacity for households to modify energy behavior. The energy consumption data for the threemonth period following the energy walkthrough in comparison with the same three-month period from the prior year was significantly lower for one household and significantly higher for another household (houses 6 and 8 shown in Figure 3a, respectively), and out of the households with available data, three reduced and five increased their aggregate energy consumption between the 2019 and 2020 three-month period. However, certain characteristics and situational occurrences must be incorporated into the analyzation process to accurately interpret the data for these and future results. This includes factors such as changes in the number of household members, significant lifestyle changes, and changes in employment and the accompanying work schedule.

Furthermore, comparing energy consumption before and after households begin energy education implies baseline energy consumption would be stable or typical for a household. The experiences and observations by the P2P energy educator, the technical intern, and other program contributors, however, revealed the inconsistency of living in financial poverty, which may result in inconsistent energy consumption within households based on both behavior and lifestyle. Additionally, several households do not and are not able to live in one home or neighborhood for long periods of time. This adds additional challenges for analyzing data and establishing trust and relationships with individuals, which will require an effective way to determine baseline energy consumption.

As previously discussed, the greatest increase in aggregate energy use among the eight households occurred during the third month following energy walkthroughs. This may indicate that implementing energy savings behaviors and modifying behaviors declines over time. However, the third month of data corresponded to the beginning of stay-at-home orders set in place in response to the COVID-19 pandemic. It is, therefore, evident that the impact of external factors and situations that are beyond the control of households, 
communities, and the program must be included and examined when analyzing energy consumption data.

Ultimately, this understanding indicates that educating households on energy behaviors and analyzing energy consumption data must account for the inconsistency certain households experience. To accurately incorporate and understand the inconsistency and unpredictability households in underserved communities endure, further research and community insight will be essential, which can include interviews with participating households from the pilot program, particularly with residents whose energy consumption decreased following the energy walkthroughs.

\subsection{P2P Energy Educator}

The P2P energy educator is a central feature of the energy reduction program that aims to provide energy savings education to households through comfortable and trusting relationships. The P2P energy educator from the pilot program understood the lifestyles of households they worked with based upon their own background, but they lacked the understanding of such experiences as an adult and as a member of the specific community. This inhibited their ability to fully connect with residents and feel confident in their role as a peer-educator and revealed that greater care must be taken when selecting an individual to fill the position of the P2P energy educator. Potential ways to address this concern include having the P2P energy educator be a resident from the community, seek out individuals who are already trusted and respected within the community, and have community members nominate and elect individuals for the position.

Before the P2P energy educator begins working with households, introductory preparation is crucial to ensure they feel confident and comfortable when interacting with participating household members. A more formalized and intentional on-boarding process is recommended based upon experiences from the first P2P energy educator and other program contributors. This process may include education and training on energy, utilities, and applicable residential programs, introductions to and meeting with local organizations, regular and consistent collaboration and communication with other program organizers, and attending community events and outreach.

Once the P2P energy educator begins interacting and meeting with individuals, it is important to establish a robust tracking and communication process. Creating a system in which the P2P energy educator is able to track and take notes of any barriers that may prevent households from being able to achieve energy savings and make energy behavior modifications will ensure there is consistency between visits and between households, that they are on top of requests and needs from particular visits, and that they are better able to tailor the program for households.

As the P2P energy educator position further evolves and develops, it will be beneficial to define all responsibilities in detail and set boundaries for the position. Energy and utility bills can be a personal subject matter for households because of its relation to money and financial security and is, therefore, an intersectional issue that brings an array of interconnected factors into the conversation of what impacts and influences a household's energy behaviors and energy consumption. There must be a boundary established to determine how far their work can expand beyond the focus of energy savings to ensure other needs are being addressed. This also includes distinguishing boundaries between the P2P energy educator and the residents to establish and maintain a trusting relationship while not going beyond their responsibilities in the program and staying within the lines of serving as a peer-educator. Clearly defining and understanding the responsibilities of the P2P energy educator is necessary for the individual themselves, other individuals working in the program, and residents. Based upon feedback and experiences from the pilot program, this will increase confidence in the P2P energy educator and their ability to have a greater impact on the program and lives of those participating. 


\subsection{Additional Recommendations}

Based upon the results and outcomes of the pilot program presented in this study, there are additional recommendations and ideas for the future of the program and its framework beyond what has been previously addressed. First, the program must take a holistic approach to finding energy savings and assisting households modify energy behaviors. The use of incentives showed positive feedback and responses among residents. To address specific needs and burdens endured by households and what may prevent them from reducing energy consumption, intentional standards and practices for incentives should be established. To expand the work beyond energy behavior and energy savings alone, it is recommended that program coordinators carefully and methodologically establish a plan and defined boundary of what the program is capable of incorporating into their work. Finding this balance will require strong program management and organization that is established at the onset of the program. Such management must also be maintained to ensure the program sustains its mission while creating greater resilience within the community.

As this study reveals, community engagement and presence are key to its success and impact. It is highly recommended to collaborate and establish partnerships with existing community programs and organizations that have the capacity to contribute to the program's efforts or are able to amplify and support the program's presence in the community. These efforts should not only focus on incorporating the program into the community but also on incorporating the community into the program and making the program be driven by the community itself. For instance, a community focus and leadership group can be established to hear insight and perspectives from community members and to tailor the program to specific communities and their needs and aspirations for the program.

To engage residents of all ages, additional programs and processes could be instituted for younger community members. The technical intern can become an intern position to create employment opportunities and skills and knowledge training for young adults and youth in the community. Partnering with community programs provides the opportunity to incorporate energy savings education in pre-existing programming for youth in the community. Working with community partners also presents the possibility of creating a community art project or display to track and present energy savings for the community. This has the potential to amplify interest, engagement, and motivation through a visual display made by the community to highlight the collective impact of energy savings.

Finally, it is recommended to reconsider and modify the energy education approach. A potential option to explore is to begin the energy education process through community and group events in an effort for the community to acquire a greater understanding and trust of the program. Feedback from this study and insight from previous studies indicate benefits of providing a casual setting for community members to socialize while also being introduced to the program by utilizing a peer-to-peer approach. It is particularly valuable for the P2P energy educator to establish and strengthen relationships with the community and individual community members. From this setting, individuals would then be able to sign-up for one-on-one interactions and meetings with the P2P energy educator to individualize energy savings behaviors and make it feasible for their lifestyle. Working on a community level first is expected to decrease intimidation or discomfort felt by residents and the P2P energy educator, which can arise when discussing what can be personal and sensitive topics and working in residents' homes. This approach also provides the opportunity to expand access to education to individuals who may not feel comfortable or have the capacity to work with a P2P energy educator on a personal level.

These insights and recommendations for an improved program design were developed from the outcomes of the pilot program. However, there are evident limitations of the current study that require further discussion. With only 11 participating households and the limited data available from household energy consumption and survey responses, the quantitative results that were collected do not provide statistical value. Rather, the results of this study are the recommendations for the improved program design, which were 
informed by the energy consumption data and survey results. Furthermore, it is critical to note that these results are also based on all 84 residences; notably, the significant variations in energy consumption among these similarly constructed houses reveals the potential in energy cost savings through behavior modifications and the lack of response, interest, and commitment to participate in the program provides value in understanding the necessity of community involvement and engagement. To investigate the efficacy of more intentional and intensive community input and engagement and, accordingly, the extent to which energy savings can be achieved through behavior modifications and peer-to-peer education in underserved communities, further research is needed.

\section{Conclusions}

Achieving residential energy savings through energy behavior modifications and a peer-to-peer education methodology in underserved communities is a complex and dynamic process, as presented in this study. It is evident that such a process requires robust community relationships that must be consistent and long-term. Because the timeframe necessary for establishing such relationships is beyond the scope of this study and the accompanying limited quantity of data, conclusive results cannot properly and effectively be drawn. However, the feedback, outcomes, and preliminary results presented provide insight into methods that contributed to the successes and drawbacks of the pilot program as well as recommendations to strengthen and scale the structure of the program.

This study indicates that a peer education approach is beneficial for gaining a genuine and individualized understanding of household barriers that exacerbate energy burdens. Areas identified as ways to increase the impact of the program include taking a holistic approach while maintaining the mission of the program, expanding the reach of the program on a household and community level, establishing a detailed and intentional longterm and short-term plan for implementation, and incorporating the community into the program itself. Further research and studies will be necessary, however, to determine the impact of the program and effectiveness of the preliminary feedback, results, and takeaways long-term. To improve community participation, and, thus, increase quantitative data, it is recommended that future programs begin with community level, grassroots efforts when conducting outreach to increase the number of participants, and focus on gaining indepth insight from participating residents, such as by conducting ethnographic, qualitative interviews. Ultimately, this study demonstrates that the framework of a peer-led energy reduction program has the potential to not only reduce household utility bills but, if properly implemented, to contribute to the development of sustainable, resilient, and empowered communities.

Future research that utilizes the improved program design insights to scale and implement the program beyond the initial neighborhood and, ultimately, beyond the US is recommended. By leveraging global partnerships within the academic and research field that have a robust and pre-existing community presence, especially in the underdeveloped world, the reality of energy poverty and the capabilities for achieving energy savings through behavior modifications from the perspective of individual households and communities can be obtained. This has significant potential to expand existing understandings of global energy poverty and uncover nuances on energy behavior, behavior change, and community engagement across cultures on a local and global scale.

Author Contributions: Conceptualization, K.H.; methodology, J.H., A.G.R., and K.H.; software, K.H.; formal analysis, J.H., A.G.R., and K.H.; investigation, J.H., A.G.R., S.R., C.F., K.H., C.O., and B.P.; data curation, J.H., A.G.R., S.R., and K.H.; writing-original draft preparation, J.H., A.G.R., and K.H.; writing-review and editing, S.R., C.F., C.O., and B.P.; supervision, S.R. and B.P.; project administration, K.H.; funding acquisition, K.H. and B.P. All authors have read and agreed to the published version of the manuscript.

Funding: This research was funded through grants from the Ohio Housing Finance Agency's (OHFA) Technical Assistance Grant and the Marianist Foundation. The views and opinions expressed in this paper do not necessarily reflect the official policy or position of OHFA. 
Institutional Review Board Statement: All subjects gave their informed consent for inclusion before they participated in the study. The study was conducted in accordance with the Declaration of Helsinki, and the protocol was approved by the Institutional Review Board of the University of Dayton on 28 June 2019 (45 CFR 46.110 Category (7)).

Conflicts of Interest: The authors declare no conflict of interest.

\section{References}

1. Special Report: Global Warming of $1.5^{\circ} \mathrm{C}$-Summary for Policymakers. Intergovernmental Panel on Climate Change. Available online: https://www.ipcc.ch/sr15/chapter/spm/ (accessed on 2 March 2021).

2. U.S. Energy-Related Carbon Dioxide Emissions, 2019. Energy Information Administration. Available online: https://www.eia. gov / environment/emissions/carbon/ (accessed on 5 November 2020).

3. Pellegrini-Masini, G.; Pirni, A.; Maran, S. Energy justice revisited: A critical review on the philosophical and political origins of equality. Energy Res. Soc. Sci. 2020, 59, 101310:1-101310:7. [CrossRef]

4. Lewis, J.; Hernández, D.; Geronimus, A.T. Energy efficiency as energy justice: Addressing racial inequities through investments in people and places. Energy Effic. 2020, 13, 419-432. [CrossRef] [PubMed]

5. Sovacool, B.K.; Dworkin, M.H. Energy justice: Conceptual insights and practical applications. Appl. Energy 2015, 142, 435-444. [CrossRef]

6. Jenkins, K.; McCauley, D.; Heffron, R.; Stephan, H.; Rehner, R. Energy justice: A conceptual review. Energy Res. Soc. Sci. 2016, 11, 174-182. [CrossRef]

7. Simcock, N.; Frankowski, J.; Bouzarovski, S. Rendered invisible: Institutional misrecognition and the reproduction of energy poverty. Geoforum 2021, 124, 1-9. [CrossRef]

8. Bouzarovski, S.; Petrova, S. A global perspective on domestic energy deprivation: Overcoming the energy poverty-fuel poverty binary. Energy Res. Soc. Sci. 2015, 10, 31-41. [CrossRef]

9. Residential Energy Consumption Survey (RECS): 2015 RECS Survey Data. Energy Information Administration. Available online: https: / www.eia.gov/consumption/residential/data/2015/ (accessed on 2 March 2021).

10. Bednar, D.J.; Reames, T.G. Recognition of and response to energy poverty in the United States. Nat. Energy 2020, 5, 432-439. [CrossRef]

11. Drehobl, A.; Ross, L.; Roxana, A. How High Are Household Energy Burdens? American Council for an Energy-Efficient Economy. Available online: https:/ / www.aceee.org/sites/default/files/pdfs/u2006.pdf (accessed on 2 March 2021).

12. Getting Energy Efficiency to the People Who Need It Most. Governing: The Future of States and Localities. Available online: https: / / www.governing.com/gov-institute/voices/col-cities-energy-efficiency-low-moderate-income-households.html (accessed on 21 February 2021).

13. Ouyang, J.; Hokao, K. Energy-saving potential by improving occupants' behavior in urban residential sector in Hangzhou City, China. Energy Build. 2009, 41, 711-720. [CrossRef]

14. Nguyen, C.P.; Su, T.D.; Bui, T.D.; Dang, V.T.B.; Nguyen, B.Q. Financial development and energy poverty: Global evidence. Environ. Sci. Pollut. Res. 2021, 28, 35188-35225. [CrossRef]

15. World Energy Outlook 2018. International Energy Agency. 2018. Available online: https://iea.blob.core.windows.net/assets/77 ecf96c-5f4b-4d0d-9d93-d81b938217cb/World_Energy_Outlook_2018.pdf (accessed on 22 July 2021).

16. Analysis of the Voluntary National Reviews Relating to Sustainable Development Goal 7: 2018. United Nations. 2018. Available online: https:/ / sustainabledevelopment.un.org/content/documents/258321159DESASDG7_VNR_Analysis2018_final.pdf (accessed on 22 July 2021).

17. Energy Access Outlook 2017: From Poverty to Prosperity. International Energy Agency. 2017. Available online: https://iea.blob. core.windows.net/assets/9a67c2fc-b605-4994-8eb5-29a0ac219499/WEO2017SpecialReport_EnergyAccessOutlook.pdf (accessed on 22 July 2021).

18. Jessel, S.; Sawyer, S.; Hernández, D. Energy, Poverty, and Health in Climate Change: A Comprehensive Review of an Emerging Literature. Front. Public Health 2019, 7, 357:1-357:19. [CrossRef]

19. Office of Community Services: LIHEAP Fact Sheet. Administration for Children \& Families: U.S. Department of Health \& Human Services. Available online: https:/ / www.acf.hhs.gov/ocs/resource/liheap-fact-sheet-0 (accessed on 2 March 2021).

20. Weatherization Assistance Program. Office of Energy Efficiency \& Renewable Energy. Available online: https: / www.energy. gov/eere/wap/weatherization-assistance-program (accessed on 2 March 2021).

21. Roth, J.; Hall, N. Assessment of LIHEAP and WAP Program Participation and the Effects on Wisconsin's Low-Income Population: An Examination of Program Effects on Arrearage Levels and Payment Patterns. ACEEE Summer Study Energy Effic. Build. 2006, 7-226-7-238. Available online: https://www.aceee.org/files/proceedings/2006/data/papers/SS06_Panel7_Paper19.pdf (accessed on 23 February 2021).

22. Lindenberg, S.; Steg, L. Normative, Gain and Hedonic Goal Frames Guiding Environmental Behavior. J. Soc. Issues 2007, 63, 117-137. [CrossRef]

23. Hines, J.M.; Hungerford, H.R.; Tomera, A.N. Analysis and Synthesis of Research on Responsible Environmental Behavior: A Meta-Analysis. J. Environ. Educ. 1987, 18, 1-8. [CrossRef] 
24. Poortinga, W.; Steg, L.; Vlek, C. Values, Environmental Concern, and Environmental Behavior. Environ. Behav. 2004, 36, 70-93. [CrossRef]

25. Thaler, R.; Sunstein, C. Nudge: Improving Decisions about Health, Wealth, and Happiness; Yale University Press: New Haven, CT, USA, 2008.

26. Grilli, G.; Curtis, J. Encouraging pro-environmental behaviours: A review of methods and approaches. Renew. Sustain. Energy Rev. 2021, 135, 110039:1-110039:14. [CrossRef]

27. Establishing a Peer Education Program. The University of Kansas: Community Tool Box. Available online: https://ctb.ku.edu/ en/table-of-contents/implement/improving-services/peer-education/main (accessed on 21 February 2021).

28. Ten Cate, O.; Durning, S. Dimensions and psychology of peer teaching in medical education. Med. Teach. 2007, 29, 546-552 [CrossRef]

29. Goldman, M.L.; Ghorob, A.; Hessler, D.; Yamamoto, R.; Thom, D.H.; Bodenheimer, T. Are Low-Income Peer Health Coaches Able to Master and Utilize Evidence-Based Health Coaching? Ann. Fam. Med. 2015, 13, S36-S41. [CrossRef] [PubMed]

30. Thorn, D.H.; Ghorob, A.; Hessler, D.; De Vore, D.; Chen, E.; Bodenheimer, T.A. Impact of Peer Health Coaching on Glycemic Control in Low-Income Patients with Diabetes: A Randomized Controlled Trial. Ann. Fam. Med. 2013, 11, 137-144.

31. Marshak, H.H.; de Silva, P.; Silberstein, J. Evaluation of a Peer-Taught Nutrition Education Program for Low-Income Parents. J. Nutr. Educ. 1998, 30, 314-322. [CrossRef]

32. Canuso, R. Low-Income Pregnant Mothers' Experiences of a Peer-Professional Social Support Intervention. J. Community Health Nurs. 2003, 20, 37-49. [CrossRef] [PubMed]

33. Twin Towers Neighborhood in Dayton, Ohio (OH), 45410 Detailed Profile. City-Data. Available online: https:/ /www.city-data. com/neighborhood/Twin-Towers-Dayton-OH.html (accessed on 19 July 2021).

34. Prototype-Twin Towers, East Dayton, Ohio. CleanEnergy4All. Available online: https://cleanenergy4all.org/project/twintowers-neighborhood/ (accessed on 5 November 2020).

35. Housing and Economic Development. East End Community Services. Available online: https://www.east-end.org/housingand-economic-development (accessed on 5 November 2020).

36. Noar, S. Transtheoretical Model and Stages of Change in Health and Risk Messaging. Oxford Research Encyclopedia of Communication. 2017. Available online: https:/ / oxfordre.com/communication/view/10.1093/acrefore/9780190228613.001. 0001/acrefore-9780190228613-e-324 (accessed on 3 March 2021).

37. Frederiks, E.R.; Stenner, K.; Hobman, E.V. The Socio-Demographic and Psychological Predictors of Residential Energy Consumption: A Comprehensive Review. Energies 2015, 8, 573-609. [CrossRef]

38. Carrus, G.; Passafaro, P.; Bonnes, M. Emotions, habits and rational choices in ecological behaviours: The case of recycling and use of public transportation. J. Environ. Psychol. 2008, 28, 51-62. [CrossRef]

39. Climate Data Online. National Centers for Environmental Information. Available online: https://www.ncdc.noaa.gov/cdo-web/ (accessed on 23 February 2021).

40. Al Tarhuni, B.; Naji, A.; Broderick, P.G.; Hallinan, K.P.; Brecha, R.J. Large Scale Residential Energy Efficiency Prioritization Enabled by Machine Learning. Energy Effic. 2019, 12, 2055-2078. [CrossRef]

41. Alanezi, A.; Hallinan, K.P.; Huang, K. Automated Residential Energy Audits Using a SmartWiFi Thermostat-Enabled Data Mining Approach. Energies 2021, 14, 2500. [CrossRef]

42. National Renewable Energy Laboratory. Dayton Electricity Rates. Electricity Local. Available online: https://www.electricitylocal. $\mathrm{com} /$ states/ohio/dayton/\#ref (accessed on 5 November 2020).

43. Greenhouse Gases Equivalencies Calculator-Calculations and References. Environmental Protection Agency. Available online: https: / / www.epa.gov/energy/greenhouse-gases-equivalencies-calculator-calculations-and-references (accessed on 2 March 2021). 